going innate immune airway responses in asthma. The relevance of this to clinical disease expression requires understanding.

\section{S43 THE EXPRESSION OF CRACM ION CHANNELS IN HUMAN LUNG MAST CELLS}

doi:10.1136/thx.2010.150912.43

${ }^{1}$ I Ashmole, ' S M Duffy, ${ }^{2} \mathrm{M}$ Leyland, ${ }^{1} \mathrm{P}$ Bradding. ${ }^{1}$ Institute for Lung Heath, Dept of Infection, Immunity and Inflammation, University of Leicester, Leicester, UK; ${ }^{2}$ Dept. of Biochemistry, University of Leicester, Leicester, UK

Introduction and objectives The influx of extracellular $\mathrm{Ca}^{2+}$ into human lung mast cells (HLMC) is essential for the IgE-dependent release of preformed granule derived mediators and newly synthesised autacoids and cytokines. However the identity of the ion channels underlying the influx of $\mathrm{Ca}^{2+}$ remains unknown. Members of the recently discovered CRACM (also known as Orai) ion channel family are candidates for this function. The channels carry $\mathrm{Ca}^{2+}$ selective currents ( $\mathrm{I}_{\mathrm{CRAC}}$ ) that are activated when endoplasmic reticulum $\mathrm{Ca}^{2+}$ stores are emptied. Here we investigate whether CRACM channels are expressed in HLMC and their possible contribution to $\mathrm{Ca}^{2+}$ influx in these cells.

Methods HLMC were purified from lung tissue by immunomagnetic affinity selection. Total RNA purified from cells was used in quantitative RT-PCR using TaqMan probes and primers (Applied Biosystems). For electrophysiology the whole cell method of patch clamp was used.

Results CRACM1, CRACM2 and CRACM3 mRNA transcripts were all readily detectable in HLMC. CRACM1 transcripts (4.50 \pm 0.51 copies $/ 10^{3}$ beta-actin transcripts, $\mathrm{n}=7$ HLMC donors) were more abundant than CRACM2 transcripts $\left(1.79 \pm 0.67\right.$ copies $/ 10^{3}$ betaactin transcripts, $\mathrm{n}=5$ ) and CRACM3 transcripts ( $3.33 \pm 0.95$ copies/ $10^{3}$ beta-actin transcripts, $\left.n=5\right)$. Consistent with the presence of CRACM transcripts, an I CRAC-like current was detected in HLMC following IgE-dependent activation and also in cells dialysed with 30 $\mu \mathrm{M}$ inositol triphosphate to empty endoplasmic reticulum $\mathrm{Ca}^{2+}$ stores. The $\mathrm{Ca}^{2+}$-selective current obtained under both conditions was blocked by the addition of $10 \mu \mathrm{M} \mathrm{La}^{3+}$, a known blocker of CRACM channels. Thus following addition of anti-IgE to 11 HLMC, current at $-120 \mathrm{mV}$ increased from $-12.1 \pm 1.1 \mathrm{pA}$ at baseline to $-34.2 \pm 2.5 \mathrm{pA}$ $(\mathrm{p}<0.0001)$ and following addition of $10 \mathrm{mM} \mathrm{La}^{3+}$ this was reduced to $-17.4 \pm 2.1$ pA. $(p=0.0003)$. When HLMC were dialysed with $\mathrm{IP}_{3}$ $(n=12)$, current increased from $-15.3 \pm 1.2 \mathrm{pA}$ to $-40.2 \pm 3.2 \mathrm{pA}$ $(\mathrm{p}<0.0001)$, and decreased to $-17.7 \pm 1.5 \mathrm{pA}(\mathrm{p}<0.0001)$ by La ${ }^{3+}$

Conclusions The presence of an $\mathrm{I}_{\mathrm{CRAC}}-$ like current and CRACM1, -2 and -3 mRNA transcripts in HLMC supports a role for CRACM channels in the influx of extracellular $\mathrm{Ca}^{2+}$ into these cells following activation. Such a role would make CRACM channels a potential therapeutic target in the treatment of asthma.

\section{S44 INCREASED EXPRESSION OF IMMUNOREACTIVE THYMIC STROMAL LYMPHOPOETIN IN SEVERE ASTHMA}

doi:10.1136/thx.2010.150912.44

${ }^{1} \mathrm{~A}$ Shikotra, ${ }^{1} \mathrm{~B}$ Hargadon, ${ }^{1} \mathrm{M}$ Shelley, ${ }^{1} \mathrm{~J}$ Bennett, ${ }^{2} \mathrm{C}$ Brightling, ${ }^{3} \mathrm{C}$ Austin, ${ }^{3} \mathrm{D} \mathrm{F}$ Choy, ${ }^{3} \mathrm{~L} C \mathrm{Wu},{ }^{3} \mathrm{~J} \mathrm{R}$ Arron, ${ }^{2} \mathrm{P}$ Bradding. ' University Hospitals of Leicester NHS Trust, Leicester, UK; ${ }^{2}$ University of Leicester, Leicester, UK; ${ }^{3}$ Genentech, Inc., South San Francisco, USA

Background Thymic stromal lymphopoetin (TSLP) is a cytokine implicated in the pathophysiology of asthma through two pathways: a TSLP-OX40L-T cell axis and a TSLP-mast cell axis. Whether these pathways operate in human asthma is unknown.
Aims To investigate whether mucosal TSLP protein expression relates to asthma severity, and distinct immunological pathways. Methods GMA-embedded bronchial biopsies from healthy subjects $(\mathrm{n}=12)$ and patients with mild (BTS step $1, \mathrm{n}=8)$, moderate (BTS steps 2 and $3, n=12$ ) and severe (BTS steps 4 and $5, n=16$ ) asthma were immunostained for TSLP, OX40, OX40L, CD83, IL-13, and inflammatory cell markers. Extent of immunostaining was correlated with clinical data.

Results Specific TSLP immunoreactivity was evident in both the airway epithelium and lamina propria of both healthy and asthmatic subjects. TSLP immunoreactivity was not present in airway smooth muscle. TSLP epithelial expression was significantly elevated in asthma as a whole compared to healthy controls $(p=0.0005)$, particularly in mild and severe disease. The number of TSLP + cells in the lamina propria was elevated in patients with severe asthma relative to other groups ( $p=0.0058)$. Co-localisation studies in 6 severe asthmatic subjects showed that $5 \%$ of TSLP + cells in the lamina propria were CD68 + macrophages and 20\% were tryptase + mast cells. There were significant inverse correlations between TSLP counts in both the asthmatic bronchial lamina propria and epithelium with the $\mathrm{FEV}_{1} /$ FVC ratio $\left(r_{s}=-0.53, p=0.002\right.$ and $\left.r_{s}=-0.40, p=0.037\right)$. Immunostaining for OX40, OX40L and CD83 in the airways was sparse, with no difference between asthmatic patients and normal control subjects. IL-13 staining was increased in non-epithelial cells within the airway epithelium in severe asthma $(p=0.033)$.

Conclusions TSLP expression is elevated in severe asthma despite high dose corticosteroid therapy. Although we did not detect activity of the TSLP-OX40L-T cell pathway within asthmatic bronchial mucosa, it is possible that this pathway operates in secondary lymphoid organs such as draining lymph nodes. The close approximation of airway stroma and mast cells suggests that the TSLP-mast cell axis, in which TSLP and IL-13 operate in a positive regulatory loop, is active in asthmatic bronchial mucosa and may be important in maintaining chronic airway inflammation.

\section{S45 FUNCTIONAL KCa3.1 $\mathrm{K}^{+}$CHANNELS ARE REQUIRED FOR HUMAN FIBROCYTE MIGRATION}

doi:10.1136/thx.2010.150912.45

S M Duffy, G Cruse, S Singh, C Doe, R Saunders, C E Brightling, P Bradding. Institute for Lung Health, Dept of Infection, Immunity, and Inflammation, University of Leicester, Leicester, UK

Background Fibrocytes are bone marrow-derived CD34 ${ }^{+}$collagen $\mathrm{I}^{+}$ cells present in peripheral blood that are implicated in the pathogenesis of tissue remodelling and fibrosis in both asthma and pulmonary fibrosis. Ion channels play key roles in cell function, but the ion channel repertoire of human fibrocytes is not known. The aim of this study was to assess whether human fibrocytes express the $\mathrm{K}_{\mathrm{Ca}} 3.1 \mathrm{~K}^{+}$channel.

Methods Human fibrocytes were isolated from peripheral blood taken from both normal and asthmatic subjects and maintained in cell culture. Channel expression was examined using RT-PCR, Western blot, and patch clamp electrophysiology. Migration assays were performed using the Transwell system.

Results Fibrocytes expressed both $\mathrm{K}_{\mathrm{Ca}} 3.1$ mRNA and protein. At baseline unstimulated fibrocytes $(n=30$ healthy cells from 7 donors, $\mathrm{n}=17$ asthmatic cells from 4 donors) demonstrated heterogeneity of the resting whole cell current, with a small outwardly rectifying current in $91 \%$ of cells, a steeply inwardly rectifying current in $30 \%$ of cells, and a linear current in $9 \%$ of cells. The $\mathrm{K}_{\mathrm{Ca}} 3.1$ opener 1-EBIO $(100 \mathrm{mM})$ elicited typical $\mathrm{K}_{\mathrm{Ca}} 3.1$ currents in $46 / 47$ cells tested. Whole cell current at $+40 \mathrm{mV}$ increased from $122 \pm 25 \mathrm{pA}$ pre-1-EBIO to $795 \pm 104$ pA post 1 -EBIO $(\mathrm{p}<0.0001)$. This was accompanied by a negative shift in reversal potential from $-29.8 \pm 3.0 \mathrm{mV}$ to $-61.8 \pm 1.6 \mathrm{mV}(\mathrm{p}<0.0001)$. 1-EBIO induced a greater current in 
asthmatic fibrocytes (1-EBIO-dependent current at $+40 \mathrm{mV} 969 \pm 216$ $\mathrm{pA} ; \mathrm{n}=17$ cells) compared to healthy fibrocytes (1-EBIO-induced current $506 \pm 94 \mathrm{pA} ; \mathrm{n}=30$ cells; $\mathrm{p}=0.029) . \mathrm{K}_{\mathrm{Ca}} 3.1$ currents were blocked by the selective $\mathrm{K}_{\mathrm{Ca}} 3.1$ blocker TRAM-34. The migration of differentiated fibrocytes induced by airway smooth muscle supernatant was inhibited by $71.1 \pm 6.9 \%$ by TRAM-34 $200 \mathrm{nM}(\mathrm{p}<0.0001)$. The CXCL12-dependent migration of fibrocyte progenitors within a freshly isolated PBMC population was reduced by $70.9 \pm 7.9 \%$ by TRAM-34 ( $p=0.003)$.

Conclusions The $\mathrm{K}^{+}$channel $\mathrm{K}_{\mathrm{Ca}} 3.1$ is expressed in human fibrocytes, and plays a key role in their migration. $\mathrm{K}_{\mathrm{Ca}} 3.1$ blockers may therefore offer a novel approach to the treatment of airway wall remodelling in asthma, and parenchymal fibrosis in idiopathic pulmonary fibrosis.

\section{S46 ACTIVATION OF TGF- $\beta$ BY AIRWAY SMOOTH MUSCLE CELLS VIA THE $\alpha V \beta 5$ INTEGRIN IN ASTHMATIC AIRWAY REMODELLING}

doi:10.1136/thx.2010.150912.46

A L Tatler, A E John, L Jolly, A J Knox, L Pang, G Jenkins. University of Nottingham, Nottingham, UK

Airway remodelling is a common feature of severe asthma. Transforming growth factor- $\beta$ (TGF- $\beta$ ) is a pro-fibrotic, pleiotropic cytokine implicated in airway remodelling. TGF- $\beta$ is sequestered in the extracellular matrix as a latent complex and requires activation to function. Lysophosphatidic acid (LPA) causes TGF- $\beta$ activation in airway epithelial cells. The study aims were to investigate the effect of LPA on TGF- $\beta$ activation by ASM cells in asthma. TGF- $\beta$ activation was assessed by a reporter cell co-culture assay, by determining expression of the TGF- $\beta$-inducible gene plasminogen activator inhibitor-1 (PAI1) and by detecting the nuclear translocation of Smad proteins. The effect of LPA on TGF- $\beta$ activation in asthma was investigated by comparing the responses of ASM cells from non-asthmatic $(n=3)$ and asthmatic $(n=3)$ donors. TGFb activation was also assessed using a chronic ovalbumin model of airway remodelling in mice. LPA induced a time, and concentration, dependent increase in TGF- $\beta$ activation by ASM cells that was abrogated by an integrin $\alpha \mathrm{V} \beta 5$ antibody. An inhibitor of cytoskeletal reorganisation inhibited the effects of LPA. Furthermore, the $\beta 2$ agonist formoterol inhibited LPA-induced PAI1 expression. Primary asthmatic ASM cells activated more TGF- $\beta$ via $\alpha \mathrm{V} \beta 5$ in response to LPA than control cells, however they did not express more $\alpha \mathrm{V} \beta 5$ on the cell surface. Phosphorylation of Smad2 and expression ofpai1 in the lungs was increased in a chronic ovalbumin model of asthmatic airway remodelling in mice. Furthermore, $\alpha \mathrm{V} \beta 5$ integrin staining and $\alpha$-smooth muscle actin staining in the ASM layer around the airways is increased in this model. Collectively, these data show that ASM cells can activate TGF- $\beta$ via the $\alpha \mathrm{V} \beta 5$ integrin and highlight a novel pathway of TGF- $\beta$ activation in ASM cells, which may be important in development of asthmatic airway remodelling.

\section{Inflammation in lung injury: the key mediators S47 RAGE-MEDIATED CYTOKINE RELEASE FROM LEUKOCYTES:}

doi:10.1136/thx.2010.150912.47

M Kaneshamoorthy, B C Creagh-Brown, A Burke-Gaffney. Unit of Critical Care, Respiratory Science, National Heart and Lung Institute Division, Faculty of Medicine, Imperial College, London, UK

Introduction Systemic inflammatory response syndrome (SIRS) is the physiological and biochemical changes that result from an
Pre versus post-op - IL-8

$n=3$

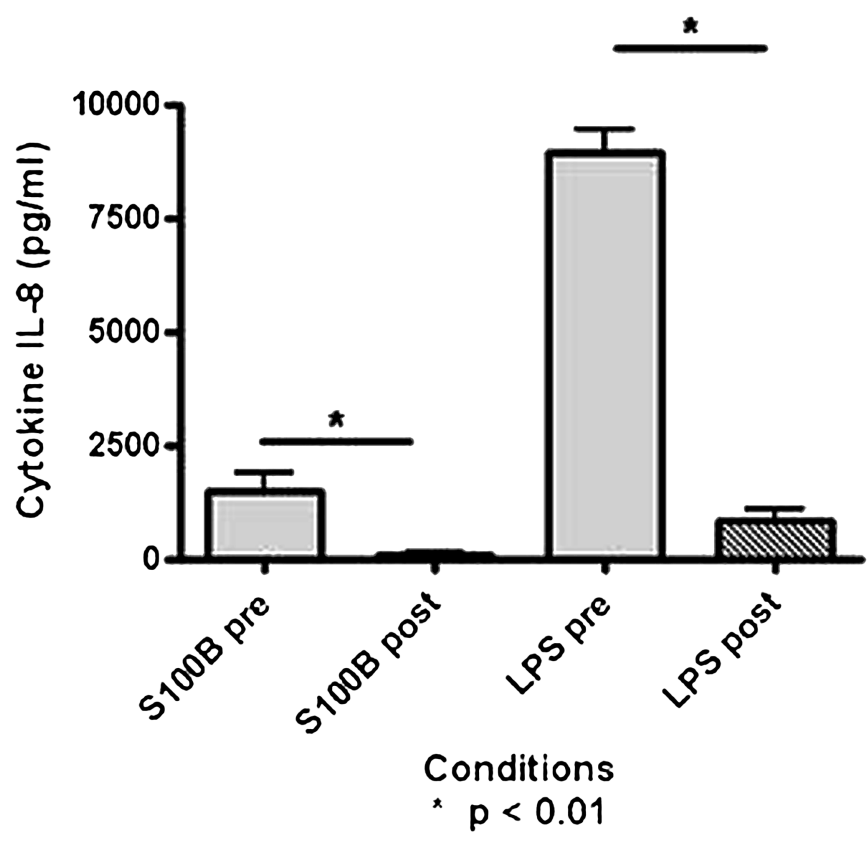

Pre versus post-op IL-10 $n=3$

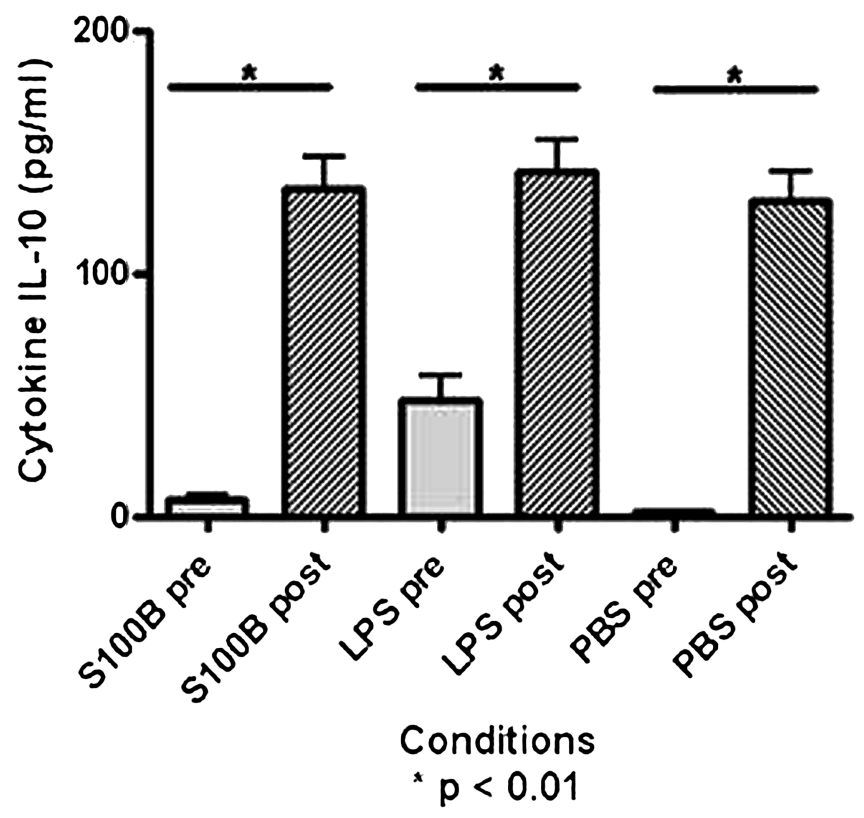

Abstract S47 Figure 1a and b Graph a shows the pre (grey) and post-bypass (striped) effects of the stimuli S100B and LPS in releasing the pro-inflammatory cytokine IL-8. The graph shows in the presence of S100B and LPS, IL-8 release is significantly reduced in post-bypass $(p<0.01)$, showing a reduced responsiveness to $S 100 B$ and LPS. Graph $b$ shows the pre and post-bypass effects of the stimuli S100B and LPS in releasing the IL-10. The graph shows that in the presence of S100B and LPS, all of the mean IL-10 release is significantly increased in post-bypass $(p<0.01)$. The mean cytokine release was calculated from nine patients done in duplicates. $p<0.01$ shows a significant difference between groups joined by a bar. PBS=Phosphate Buffered Saline; LPS=lipopolysaccharide. 